\title{
Dietary DHA and health: cognitive function ageing
}

\author{
Carlos Cardoso ${ }^{1,2 *}$, Cláudia Afonso ${ }^{1,2 *}$ and Narcisa M. Bandarra ${ }^{1,2}$ \\ ${ }^{1}$ Department of Sea and Marine Resources, Portuguese Institute for the Sea and Atmosphere (IPMA, IP), Rua Alfredo \\ Magalhães Ramalho 6, 1495-006 Lisbon, Portugal \\ ${ }^{2}$ CIIMAR, Interdisciplinary Centre of Marine and Environmental Research, University of Porto, Rua dos Bragas 289, 4050-123 \\ Porto, Portugal
}

\section{Abstract}

DHA is a key nutritional $n-3$ PUFA and needs to be supplied by the human diet. DHA is found in significant amounts in the retinal and neuronal cell membranes due to its high fluidity. Indeed, DHA is selectively concentrated in the synaptic and retinal membranes. DHA is deemed to display anti-inflammatory properties and to reduce the risk of CVD. Consumption of larger amounts of DHA appears to reduce the risk of depression, bipolar disorder, schizophrenia and mood disorders. Conversely, it has been shown that loss of DHA from the nerve cell membrane leads to dysfunction of the central nervous system in the form of anxiety, irritability, susceptibility to stress, dyslexia, impaired memory and cognitive functions, and extended reaction times. DHA plays an important role in ensuring a healthy ageing, by thwarting macular degeneration, Alzheimer's disease, and other brain disorders at the same time as enhancing memory and strengthening neuroprotection in general. A reduced level of DHA is associated with cognitive decline during ageing. Different mechanisms for this fundamental DHA role have been put forward. Namely, neuroprotectin D1, a DHA derivative, may support brain cell survival and repair through neurotrophic, anti-apoptotic, and anti-inflammatory signalling. Many of the effects of DHA on the neurological system may be related to signalling connections, thus leading to the study of the related signalolipidomics. Therefore, the present review will focus on the influence of DHA deficiency upon ageing, with specific emphasis upon neurological disorders related to cognitive function and mental health.

\section{Key words: DHA: Marine sources: Ageing: Cognitive disorders: Mental health}

\section{Introduction}

In developed countries, population ageing is a major demographic trend and will remain so in the next decades. Accordingly, health issues concerning the elderly have increased in importance and have entailed an ever-growing level of economic costs. Among these health issues, loss of memory and alterations in behaviour associated with declining brain function have a large impact on society and the economy. These changes with ageing are also key symptoms of degenerative brain diseases, such as Alzheimer's disease (AD) and other dementia forms ${ }^{(1)}$. Furthermore, there are many forms of chronic debilitating brain disorders besides dementias. It has been claimed that in the next years the impact of the wide array of brain disorders will possibly surpass that of CVD and cancer taken together ${ }^{(2)}$. Therefore, it is of paramount importance to achieve a deeper knowledge of the conditions for optimal brain function and cognition. It is important to point out that prevention is more effective than treatment in curbing the societal and economic costs. Taking this into account, nutrition may have a very significant role for this objective.
In fact, there are aspects associated with nutrition that affect the risk of cognitive function decline and neural and psychiatric outcomes.

DHA, one of the most important marine $n$ - 3 PUFA, may have a strong influence on brain health ${ }^{(1)}$. Indeed, consumption of larger amounts of $n-3$ PUFA, particularly DHA, appears to reduce the risk of depression ${ }^{(3)}$, including postpartum depression, bipolar disorder (manic depression), schizophrenia, and mood and behaviour disorders ${ }^{(4)}$. It has also been hypothesised a connection between DHA in the diet and in the nerve cell membrane and the risk of dysfunction of the central nervous system in the form of anxiety ${ }^{(5)}$, irritability, susceptibility to stress $^{(6)}$, dyslexia ${ }^{(7)}$, stereotypic behaviour, aggressiveness ${ }^{(8)}$, reduced learning capacity ${ }^{(4)}$, impaired memory and cognitive functions, and extended reaction times ${ }^{(9)}$.

The present review will focus on the role of DHA in the nervous system and cognitive function as well as in the prevention of cognitive decline associated with ageing. The state-of-the-art in these scientific areas of research will be analysed taking into account the DHA chemical form (Fig. 1), that is, the wider chemical structure where DHA is bound (TAG, NEFA, ethyl ester

Abbreviations: AD, Alzheimer's disease; ALA, $\alpha$-linolenic acid; $\beta$-APP, $\beta$-amyloid precursor protein; FA, fatty acid; MCI, mild cognitive impairment; NeuroPs, neuroprostanes; NPD1, neuroprotectin D1; PC, phosphatidylcholine; PL, phospholipid; RCT, randomised controlled trial; RDI, recommended daily intake.

* Corresponding authors: Carlos Cardoso, email carlos.cardoso@ipma.pt; Cláudia Afonso, email cafonso@ipma.pt 
<smiles></smiles>

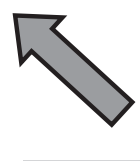

DHA<smiles>O=CO</smiles>

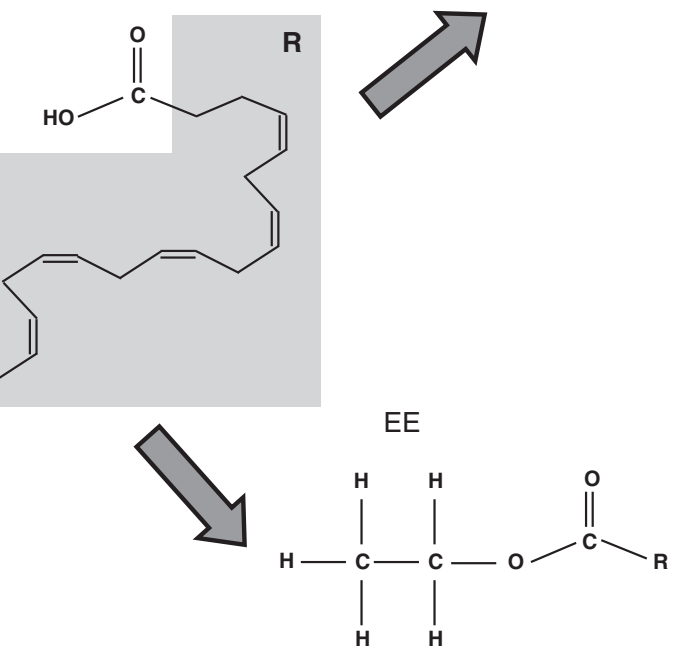

Fig. 1. Chemical structure of the different chemical forms in which DHA may be found. PL, phospholipid; R', choline, serine, ethanolamine, etc.; EE, ethyl ester.

and phospholipid (PL)) and its effects on DHA bioaccessibility and bioavailability.

\section{DHA and its role in cognitive ageing: evidence discussion}

Ageing and the cognitive function decline associated with it pose a great challenge to societies in developed countries. The loss of cognitive abilities may vary immensely in kind and degree and may affect not only elderly, but also middle-aged individuals. In the most serious situations, pathologies are identified. As aforementioned, there are many forms of chronic debilitating brain disorders, nutrition being a possible key to the prevention and mitigation of some of their effects. DHA plays an important role in ensuring healthy ageing, by possibly thwarting macular degeneration, AD and Parkinson's disease, and other brain disorders at the same time as enhancing memory and strengthening neuroprotection in general. A reduced level of DHA in the blood is associated with cognitive decline during ageing ${ }^{(10)}$. An overview of the various studies concerning the impact of DHA on AD (and other cognitive decline situations) as well as on healthy individuals is presented in Table 1.

There are several important studies correlating dietary DHA and cognitive function ageing effects. These studies relate to different human populations that can be healthy or presenting mild cognitive impairment (MCI)/AD/other cognitive function disorders.

Some interesting studies, either observational or randomised controlled trials (RCT), have been carried out with healthy populations ${ }^{(11-13)}$. For instance, in a community-dwelling cohort, levels of $\alpha$-linolenic acid (ALA), EPA and DHA were assessed in serum PL of volunteers not taking fish oil supplements ${ }^{(11,14)}$. It was found out that only the associations between serum PL DHA and non-verbal reasoning and working memory remained after adjustment for participant education and vocabulary. Moreover, DHA increased cognitive performance in an RCT involving mentally healthy individuals older than 55 years ${ }^{(13,15)}$. Daily supplementation of $900 \mathrm{mg}$ of algal (Schizochytrium sp.) DHA for 24 weeks was associated with significantly lower paired associative learning errors than the placebo case. Similar results were attained by an RCT study ${ }^{(12)}$ on executive functions and neuroimaging in a group of healthy subjects whose age ranged between 50 and 75 years. The authors registered a benefit in executive function including verbal fluency. They also found alterations in white matter microstructural integrity (interpreted as beneficial) as well as increases in gray matter volume in the frontal, temporal, parietal and limbic areas ${ }^{(12)}$. In a large cohort of Chinese adults (average age of 65 years; part of the Singapore Longitudinal Aging Studies (SLAS)), daily consumption of fish oil supplements was associated with higher Mini-Mental State examination scores and a lower risk of cognitive decline over a $1 \cdot 5$-year period ${ }^{(16)}$.

All these studies involving healthy subjects have some drawbacks. In fact, while the study by Witte et al. ${ }^{(12)}$ involved a very small population ( $n$ 65), the SLAS did not control the level of DHA intake. Therefore, both studies' conclusions are weakened by these shortcomings. The study by Yurko-Mauro et $a l .{ }^{(13)}$ seems better designed and more robust than others and clearly points to positive effects of $0.9 \mathrm{~g}$ DHA/d. However, the study by Velho et al ${ }^{(17)}$ did not find an effect of any PUFA on cognitive function. Hence, though studies on healthy elderly seem to point to a beneficial net effect of DHA on cognitive ageing, evidence is still far from convincing, further studies being required. 
Table 1. Overview of some significant intervention and observational studies concerning the effects of DHA on the cognitive decline due to ageing

\begin{tabular}{|c|c|c|c|c|c|c|c|}
\hline Type of study & $\begin{array}{l}\text { Study length } \\
\text { (months) }\end{array}$ & $\begin{array}{l}\text { Subjects } \\
(n)\end{array}$ & $\begin{array}{c}\text { Age } \\
\text { (years) }\end{array}$ & $\begin{array}{l}\text { DHA intake } \\
\qquad(\mathrm{g} / \mathrm{d})\end{array}$ & DHA source/form & Outcome & Reference \\
\hline Observational study & - & 280 & $35-54$ & - & - & $\begin{array}{l}\text { Positive association between DHA and non-verbal } \\
\text { reasoning and working memory in healthy volunteers }\end{array}$ & (11) \\
\hline $\begin{array}{l}\text { Prospective cohort } \\
\text { study }\end{array}$ & 18 & 1475 & $\geq 55$ & - & Fish oil/TAG & $\begin{array}{l}\text { Daily consumption of fish oil supplements was associated } \\
\text { with higher Mini-Mental State examination scores and } \\
\text { lower cognitive decline }\end{array}$ & (16) \\
\hline $\begin{array}{l}\text { Cross-sectional and } \\
\text { prospective study }\end{array}$ & $5-12$ & 187 & $>65$ & - & - & $\begin{array}{l}\text { The exact effect of } n \text {-3 PUFA intake on cognitive function of } \\
\text { elderly was unclear, warranting further study }\end{array}$ & (17) \\
\hline $\begin{array}{l}\text { Randomised } \\
\text { controlled trial }\end{array}$ & 6 & 65 & $50-75$ & - & Fish oil/TAG & $\begin{array}{l}\text { DHA (and other } n \text {-3 PUFA) was beneficial in executive } \\
\text { function including verbal fluency in healthy subjects }\end{array}$ & (12) \\
\hline $\begin{array}{l}\text { Randomised } \\
\text { controlled trial }\end{array}$ & 6 & 485 & $\geq 55$ & 0.9 & Algal/TAG & $\begin{array}{l}\text { DHA associated with significantly lower paired associative } \\
\text { learning errors in healthy subjects }\end{array}$ & (13) \\
\hline $\begin{array}{l}\text { Randomised } \\
\text { controlled trial }\end{array}$ & 6 & 23 & $55-90$ & 0.7 & Fish oil/TAG & $\begin{array}{l}\text { DHA improved Alzheimer's Disease Assessment Scale } \\
\text { score in subjects with mild cognitive impairment }\end{array}$ & (18) \\
\hline $\begin{array}{l}\text { Randomised } \\
\text { controlled trial }\end{array}$ & 3 & 21 & 68.1 (SD 6.3) & 0.2 & - & $\begin{array}{l}\text { DHA improved immediate memory and attention score in } \\
\text { subjects with mild cognitive impairment }\end{array}$ & (19) \\
\hline $\begin{array}{l}\text { Randomised } \\
\text { controlled trial }\end{array}$ & 12 & 36 & $\geq 60$ & $1 \cdot 3$ & Fish oil & $\begin{array}{l}\text { DHA provided benefit for several measures of memory } \\
\text { function in subjects with mild cognitive impairment }\end{array}$ & (20) \\
\hline Observational study & 31 & 186 & $65-84$ & - & - & $\begin{array}{l}\text { Only high DHA and other } n-3 \text { PUFA intake evidenced a } \\
\text { borderline non-significant trend for a protective effect } \\
\text { against the development of mild cognitive impairment }\end{array}$ & (23) \\
\hline Observational study & 48 & 397 & $55-90$ & - & Fish oil & $\begin{array}{l}\text { Although a causal effect of fish oil supplement use on } \\
\text { cognition cannot be concluded from results, they } \\
\text { highlight the need for future research }\end{array}$ & (22) \\
\hline Observational study & - & 5395 & $\geq 55$ & - & - & DHA was not associated with $A D$ risk & (29) \\
\hline Observational study & - & 815 & $65-94$ & - & - & DHA was associated with reduced risk of $A D$ & (25) \\
\hline Observational study & - & 899 & $55-88$ & - & - & $\begin{array}{l}\text { Top quartile of plasma phosphatidylcholine DHA was } \\
\text { associated with reduced risk of } A D\end{array}$ & (26) \\
\hline $\begin{array}{l}\text { Randomised } \\
\text { controlled trial }\end{array}$ & 6 & 23 & $55-90$ & 0.7 & Fish oil/TAG & $\begin{array}{l}\text { DHA produced no difference in Alzheimer's Disease } \\
\text { Assessment Scale score in AD subjects }\end{array}$ & (18) \\
\hline $\begin{array}{l}\text { Randomised } \\
\text { controlled trial }\end{array}$ & 3 & 8 & $67 \cdot 0$ (sD 6.3) & 0.2 & - & $\begin{array}{l}\text { DHA did not improve immediate memory and attention } \\
\text { score in AD patients }\end{array}$ & (19) \\
\hline $\begin{array}{l}\text { Randomised } \\
\text { controlled trial }\end{array}$ & 18 & 402 & 76 (sD 8.7) & $2 \cdot 0$ & Algal/TAG & $\begin{array}{l}\text { DHA provided benefit for cognitive score in ApoE4 allele- } \\
\text { negative AD patients }\end{array}$ & (32) \\
\hline
\end{tabular}

$A D$, Alzheimer's disease. 
For individuals with MCI, some interesting studies ${ }^{(18-20)}$ have also been carried out. The evidence has been recently reviewed $^{(21)}$. Namely, the Memory Improvement After DHA Study (MIDAS) demonstrated that DHA may be advantageous in healthy adults with a mild memory complaint ${ }^{(13)}$, thereby emphasising the role of prevention. Another study, Lee et al. ${ }^{(20)}$, has reported a benefit for several measures of memory function in a group of elderly patients with MCI. Furthermore, in an RCT study, DHA provided benefit for several measures of memory and attention score in subjects with $\mathrm{MCI}^{(19)}$. However, in a study by Daiello et $a l .{ }^{(22)}$, it was concluded that a causal effect of fish oil supplement use on cognition was not proven, further research being warranted. On the other hand, in the Italian Longitudinal Study on Aging, there was no significant effect on the protection against the development of $\mathrm{MCI}^{(23)}$. These latter studies oppose the view that benefits of DHA are easier to detect during ageing whenever there is some MCI or memory complaint or possibly if an individual is under the influence of some physical or mental stressors ${ }^{(21)}$

A critical appraisal of these studies relating to MCI raises doubts about the beneficial action of DHA on MCI onset and development. The more positive results were attained in studies with small populations (thirty-six or lower) ${ }^{(18-20)}$. The studies with larger populations (186 or higher) did not show significant results $^{(22,23)}$, but they were observational studies where high DHA intakes were not tested by a significant share of the subject set. Accordingly, the protective role of DHA in MCI is still dubious.

Nevertheless, the effects of DHA on cognitive ageing, MCI and dementia other than $\mathrm{AD}$ have been more supported by evidence than those on $\mathrm{AD}$. Whereas, according to some authors, DHA improved cognitive abilities in individuals with MCI, the effects on AD patients were not obvious ${ }^{(10,18,19)}$. Indeed, it has been mentioned that once $\mathrm{AD}$ is clinically evident, supplementation trials show no significant effect of DHA on $\mathrm{AD}^{(24)}$. Nevertheless, several prospective observational studies clearly point to a protective effect of higher DHA intake against risk of $\mathrm{AD}^{(25,26)}$. Hence, prevention is more effective than treatment. This assessment of the observational studies has been shared by different review papers ${ }^{(24,27,28)}$. On the other hand, there are other observational studies that did not find any association between DHA intake and AD risk ${ }^{(29)}$. A meta-analysis reviewing the association of $n-3$ PUFA and DHA with $\mathrm{AD}$ incidence found no significant evidence ${ }^{(30)}$. However, in some populations, such as the Dutch ${ }^{(29)}$, fish consumption and DHA intake are quite low ${ }^{(31)}$, thus entailing statistical problems given the very low number of subjects with a DHA intake high enough to reduce $\mathrm{AD}$ incidence. Furthermore, another interesting study ${ }^{(32)}$, the Alzheimer's Disease Cooperative Study, found out that DHA did not produce any benefit in the primary outcomes, but observed a benefit for cognitive score in ApoE4 allele-negative patients. Indeed, $\mathrm{AD}$ patients in this group had a significantly lower decline in the Alzheimer's Disease Assessment Scale score over 18 months with a daily dosage of $2 \mathrm{~g}$ of DHA.

A comparison between the studies concerning DHA and AD (Table 1) shows that some studies do not have a representative population sample ${ }^{(18,19)}$ and, as such, their significance is quite weakened. The Dutch study ${ }^{(29)}$ seems much more solid and representative. The other observational studies are more modest and show beneficial DHA effects on $\mathrm{AD}$ that were not found in the Dutch study ${ }^{(25,26)}$. The RCT study by Quinn et al $^{\left({ }^{(32)}\right.}$ may harbinger a new generation of studies that are supported by a priori genetic analysis. This will provide much more insight. Meanwhile, evidence connecting DHA intake and containment of $\mathrm{AD}$ progression after its onset is very insufficient.

Whether healthy or MCI or AD subjects, the assessed studies do not provide incontrovertible outcomes. It is possible that the beneficial effects of DHA concern solely AD and MCI prevention and be entirely absent once clinical conditions, especially if severe $(\mathrm{AD})$, are already present. But, results do not allow for such conclusion. Perhaps, more importantly, future studies should always separate population groups in accordance to their genes, since some causal links may only occur in specific genotypes. Studies encompassing larger populations and longer periods are also warranted.

\section{DHA and its role in cognitive ageing: dose-response and mechanisms}

The calibration of the DHA dosages for achieving a significant response is another issue that requires new studies. Some of the daily DHA dosages are quite high. For instance, in order to achieve $2 \mathrm{~g} / \mathrm{d}$ of DHA, a daily meal of $130 \mathrm{~g}$ of Atlantic mackerel or $120 \mathrm{~g}$ of Atlantic salmon may be required (Table 2). Therefore, it would be difficult to achieve such high DHA intakes without supplements. Moreover, in future RCT, the issue of DHA bioavailability (see the 'Dietary sources of DHA, bioaccessibility and bioavailability' section) should be taken into account - for instance, the same DHA dosage given to different individuals can lead to different levels of bioavailable DHA as a result of changes in the functioning of the digestive system due to age and disease - and a better selection of DHA supplements (including chemical binding form) should be ensured.

For those studies involving AD patients, it has been observed that though DHA intake is low, brain DHA levels are frequently similar to the controls, thus suggesting that low DHA intake leads to low plasma DHA, but does not necessarily decrease brain $\mathrm{DHA}^{(24)}$. Accordingly, these authors have claimed that animal models involving dietary $n$-3 PUFA deficiency in order to deplete brain DHA may not be adequate in $\mathrm{AD}$ research. Moreover, it has been claimed that the fatty acid (FA) profile of plasma total lipids is not an appropriate measure of DHA status in $\mathrm{AD}$ because it seems to mask lower DHA in plasma PL offset by higher DHA in plasma cholesteryl esters ${ }^{(33,34)}$. Hence, it is of paramount importance to analyse DHA in each lipid class. AD has been associated with changes in plasmalogen choline as well as in the amount of DHA found in different $\mathrm{PL}^{(35)}$.

In the mechanistic analysis of the link between DHA and cognitive function, it should be noted that DHA is by far the main $n$-3 PUFA present in the brain - its content within brain FA is $12-15 \%^{(36)}$ - where it is predominantly located in neuronal membranes of the grey matter, especially in synapses ${ }^{(24)}$. In addition, the brain FA-binding protein preferentially binds DHA (and other $n$-3 PUFA) ${ }^{(37)}$, leading to higher levels of DHA incorporation in the molecular structures of the membranes ${ }^{(38)}$. 
Table 2. Average DHA content $(\mathrm{mg} / 100 \mathrm{~g})$ in different marine sources, not subjected to any culinary process ${ }^{(112,113,130-132)}$

\begin{tabular}{|c|c|c|c|}
\hline Category & Product & $\begin{array}{l}\text { DHA content } \\
(\mathrm{mg} / 100 \mathrm{~g})\end{array}$ & $\begin{array}{l}\mathrm{DHA} \\
\text { richness }\end{array}$ \\
\hline \multirow[t]{2}{*}{ Bivalves } & Common cockle & 215 & Poor \\
\hline & Grooved carpet shell & 55 & Poor \\
\hline \multirow[t]{4}{*}{ Cephalopods } & Common cuttlefish & 38 & Poor \\
\hline & Common octopus & 129 & Poor \\
\hline & European squid & 417 & Medium \\
\hline & Flying squid & 225 & Poor \\
\hline \multirow[t]{3}{*}{ Crustaceans } & Norway lobster & 77 & Poor \\
\hline & Red shrimp & 28 & Poor \\
\hline & Rose shrimp & 29 & Poor \\
\hline \multirow[t]{30}{*}{ Fish } & Alfonsino & 48 & Poor \\
\hline & Atlantic cod & 42 & Poor \\
\hline & Atlantic mackerel & 1580 & Rich \\
\hline & Atlantic salmon & 1773 & Rich \\
\hline & Auxillary seabream & 327 & Medium \\
\hline & Black scabbardfish & 171 & Poor \\
\hline & Blackspot seabream & 490 & Medium \\
\hline & Chub mackerel & 2128 & Rich \\
\hline & Common sole & 29 & Poor \\
\hline & European conger & 425 & Medium \\
\hline & European eel & 3447 & Rich \\
\hline & European hake & 155 & Poor \\
\hline & European plaice & 153 & Poor \\
\hline & Gilthead seabream & 1207 & Rich \\
\hline & Greater forkbeard & 26 & Poor \\
\hline & Horse mackerel & 363 & Medium \\
\hline & Ling & 21 & Poor \\
\hline & Meagre & 147 & Poor \\
\hline & Monkfish & 38 & Poor \\
\hline & Northern bluefin tuna & 420 & Medium \\
\hline & Rainbow trout & 387 & Medium \\
\hline & Red porgy & 45 & Poor \\
\hline & Rubberlip grunt & 79 & Poor \\
\hline & Sardine & 1169 & Rich \\
\hline & Sea bass & 599 & Rich \\
\hline & Silver scabbardfish & 460 & Medium \\
\hline & Smooth hound & 51 & Poor \\
\hline & Swordfish & 829 & Rich \\
\hline & Thornback ray & 44 & Poor \\
\hline & Wreckfish & 418 & Medium \\
\hline \multirow[t]{4}{*}{ Microalgae } & Amphidinium sp. $\mathrm{S} 1^{*}$ & 677 & Poort \\
\hline & Isochrysis galbana NIVA-4/91* & 1580 & Medium $†$ \\
\hline & Prorocentrum triestinum $\mathrm{S} 2^{*}$ & 752 & Poort \\
\hline & $\begin{array}{l}\text { Thraustochytrium aureum } \\
\text { ATCC } 34304\end{array}$ & 6590 & Richt \\
\hline \multirow[t]{5}{*}{ Seaweeds } & Ascophyllum nodosum ${ }^{\star}$ & 40 & Poor \\
\hline & Fucus spiralis* & 83 & Poor \\
\hline & Fucus vesiculosus* ${ }^{\star}$ & 91 & Poor \\
\hline & Laminaria digitata* & 16 & Poor \\
\hline & Pelvetia canaliculata* & 127 & Poor \\
\hline
\end{tabular}

* For microalgae and seaweeds, DHA contents are given in mg/100 g DM.

† For microalgae and seaweeds, richness was assessed assuming $20 \% \mathrm{DM}$ as is usually the case in seafood.

DHA is supplied to the central nervous system by the liver, where DHA attained from food is taken up and distributed to other organs ${ }^{(39)}$. Besides, though there is evidence suggesting the expression and functional role of FA transporters at the blood-brain barrier ${ }^{(40)}$, DHA can reach the brain by simple diffusion through this barrier ${ }^{(41)}$. On the other hand, the dietary level of $\alpha$-linolenic acid (ALA; $18: 3 n$-3), a precursor of DHA, does not correlate well with the level of DHA in the human body, making it advisable, for instance, to supplement the nursing mother's diet with $\mathrm{DHA}^{(42)}$. Furthermore, it should be remarked that plasma or erythrocyte DHA does not correlate well with DHA in the brain cells ${ }^{(24,43-45)}$.

DHA is highly enriched in the PL of the synaptic plasma membrane and synaptic vesicles ${ }^{(46)}$. Regarding this issue, it is worth analysing the pathways leading to the synthesis of some important PL. Phosphatidylcholine (PC), a fundamental brain PL, is synthesised through the Kennedy pathway ${ }^{(47)}$ from three precursors: choline, a pyrimidine, and, typically, a PUFA (either DHA or other PUFA). Phosphatidylethanolamine (PE) may be synthesised from a PUFA and a pyrimidine. These precursors act by enhancing the substrate saturation of enzymes that bring about the incorporation of the precursors in PC and phosphatidylethanolamine ${ }^{(48)}$. In accordance with this, it has been reported that synaptic proteins and PL are increased in gerbil brain by joint administration of uridine and $\mathrm{DHA}^{(48)}$. Furthermore, it was found that continuous supply of DHA, but not arachidonic acid (20:4n-6), may lead to an increase in brain phosphatide and synaptic protein levels according to animal models ${ }^{(49)}$. Phosphatidylserine is also very important and abundant in the human brain and typically contains significant amounts of $\mathrm{DHA}^{(50)}$. It is known that throughout childhood development DHA is accumulated within the brain PL, PC and phosphatidylethanolamine ${ }^{(51)}$.

Differently from EPA, DHA is not a source for eicosanoid synthesis, rather exerting influence directly and indirectly. DHA can also be converted to EPA by a retroconversion reaction, thereby leading to the formation of various eicosanoid metabolites ${ }^{(52)}$. The DHA derivatives produced by oxidation reactions have also importance and are usually termed docosanoids ${ }^{(53)}$. Such compounds bear resemblance to eicosanoids and are deemed as potential mediators of the biochemical processes in the central nervous system ${ }^{(53)}$. DHA may also generate trans-4-hydroxy-2hexenal (4-HHE) as a result of peroxidation. This oxidation product, 4-HHE, has been shown to be toxic to primary cultures of cerebral cortical neurons ${ }^{(54)}$. The formation of 4-HHE seems to follow an oxidation pathway different from that generating docosanoids. Hence, DHA may undergo different biochemical transformations as a function of the prevailing conditions and lead to distinct effects on the central nervous system.

Docosanoids include neuroprotectin D1 (NPD1), maresins, neuroprostanes (NeuroPs), and related $22-\mathrm{C}$ derivatives ${ }^{(55)}$. The NeuroPs are structurally related to prostaglandins and constitute a large family of oxidised cyclopentanoid derivatives. NeuroPs are derived through a cascade of non-enzymic radical reactions from the non-enzymic peroxidation of DHA in neurons ${ }^{(56)}$. However, it has also been shown that lipoxygenase inhibitors block the synthesis of many docosanoids ${ }^{(57)}$. Interestingly, it has been suggested that these DHA derivatives might be neuroprotective ${ }^{(58)}$. The research into the role of NPD1 has brought forth evidence of such a neuroprotective effect ${ }^{(59)}$.

NPD1 is attained from the selective oxygenation of DHA by the enzyme 15 -lipoxygenase- ${ }^{(60)}$. NPD1 leads to homeostatic signalling in response to cellular and systemic imbalances ${ }^{(61)}$. In particular, the positive regulatory actions of NPD1 together with DHA follow different interdependent mechanisms ${ }^{(62-65)}$. First, membrane properties encompassing lipid bilayer fluidity and membrane rafts are important for their biophysical characteristics. Another mechanism involves the recruitment and up-regulation of anti-apoptotic members of the $\mathrm{BCl}-2$ gene family. Moreover, the 
modulation of kinase-mediated $\mathrm{Bcl}-2$ gene family phosphorylation is affected. The activation of inflammatory signalling mediators (for instance, the PG-synthesising arachidonic FA enzyme cyclooxygenase-2) is repressed. Finally, the expression of proapoptotic signalling is also repressed.

Different mechanisms for the DHA role as a protective agent against cognitive decline have been put forward. Namely, NPD1 may support brain cell survival and repair through neurotrophic, anti-apoptotic and anti-inflammatory signalling. Indeed, many of the effects of DHA on the neurological system may be related to signalling connections, thus leading to the study of the related signalolipidomics. However, the action of NPD1 as a possible modulating agent of transport mediated by ApoE and its effect on $\beta$-amyloid precursor protein ( $\beta$-APP) processing, soluble amyloid precursor protein $\alpha$ fragment (SAPP- $\alpha$ ) or amyloid- $\beta$ peptide speciation, generation, and secretion during ageing, and in cytokine-, hypoxia- and oxidation-stressed human brain cell models of $\mathrm{AD}$ are not fully understood. DHA itself has been linked to these events ${ }^{(64,66,67)}$. It is still unsettled if, under those conditions, NPD1 is formed from DHA or if there are alternative mechanisms for DHA $\operatorname{action}^{(63)}$

However, there are aspects of the NPD1 action that need to be better understood, such as, the impact on the biophysics and kinetics of the membrane-embedded secretase-mediated cleavage mechanisms of $\beta$-APP ${ }^{(66,68)}$. Moreover, the effect of NPD1 on specific secretase activities is a still unexplored field, which deserves more attention, given its importance to the design of more effective and selective amyloid- $\beta$ peptidelowering agents ${ }^{(68,69)}$.

The Alzheimer's Disease Cooperative Study AD study ${ }^{(32)}$ also suggests other biochemical interactions of DHA, given the sensitivity of ApoE4 allele-negative patients to DHA. It is known that ApoE can interact with various receptors in the brain, in neurons, astrocytes and in capillary endothelial cells at the blood-brain barrier ${ }^{(70,71)}$. ApoE4 is a lipid transporter, which may limit DHA transport in the brain. A comparison between old ApoE4 carriers with ApoE4 allele-negative individuals (carrying ApoE2 or ApoE3 alleles) points to a shorter DHA whole-body half-life in the former after an oral dose of $\left[{ }^{13} \mathrm{C}\right]$ $\mathrm{DHA}^{(72)}$. It has been reported that an accumulation of DHA in the blood is associated with lower concentrations in cerebral tissue of ApoE4 mice, taking ApoE2 animals as a reference ${ }^{(73)}$. Such an inverse relationship between plasma and brain DHA contents suggests that plasma levels ${ }^{(74)}$ may reflect defective distribution in the brain rather than being a good correlate of brain DHA content. So, it seems that ApoE4 leads to less DHA being transported into the brain, thereby causing a deleterious effect in $\mathrm{AD}^{(21)}$.

A further mechanism relating DHA dietary intake and cognitive function ageing may involve the role of DHA in inflammatory processes. Indeed, DHA and EPA are deemed to display some anti-inflammatory properties ${ }^{(75,76)}$, thereby offsetting the pro-inflammatory effects of $n-6$ PUFA $^{(76)}$. For diseases having a recognised central role of inflammation to the pathology such as asthma or rheumatoid arthritis, DHA supplementation in the diet may be protective. The DHA-derived docosanoids are potent endogenous anti-inflammatory and pro-resolving chemical mediators $^{(77)}$. They may reduce chronic inflammation by attenuating NF-kB, thereby modulating the expression of pro-inflammatory cytokines. On the other hand, abundant evidence indicates that inflammatory processes are active in $\mathrm{AD}^{(78)}$. Epidemiological studies indicate a lower prevalence of $\mathrm{AD}$ in individuals treated with non-steroidal anti-inflammatory drugs, but clinical trials have not yielded strong effects ${ }^{(79)}$. It is known that $\mathrm{AD}$ is related to the activation of microglia by different factors, including $\beta$-APP and pro-inflammatory cytokines ${ }^{(80)}$. Microglia increase the levels of some cytokines, such as IL-6, and TNF- $\alpha$, which may generate deviations from the normal neuronal function $^{(81)}$.

Besides, DHA incorporation into the cell membranes modulates the efficiency of numerous membrane transporters and enzymes ${ }^{(82)}$. The incorporation of DHA into cell membranes is of great importance, since many essential cellular processes take place in and on membranes ${ }^{(83)}$. These processes are affected by the biochemical and biophysical properties of organelle membranes. Precisely, the lipid composition of these membranes influences the membrane properties, which, in turn, decisively exert an effect upon the activity of membrane-embedded proteins $^{(84)}$. For instance, membrane thickness can affect the location of proteins.

DHA may also affect directly the physical properties of membranes, which depend on PL that are known to have a large importance in the neural membranes. For instance, PL, such as glycerophospholipids and sphingolipids, and sterols are prominent lipid classes in the membranes, but there is a large diversity of other minor lipid components ${ }^{(85)}$. The physical properties of membranes are affected both by the head groups and the hydrocarbon chains of lipid molecules. These effects can be tremendous not only on the properties, but also on the processes occurring within the membranes, even with subtle changes in lipid composition ${ }^{(83)}$. For instance, while a hypothetical bilayer of PC with two chains of a SFA such as stearic acid (18:0) displays a packed ordered state without any diffusion of lipid substances, a bilayer of PC with two DHA chains exhibits a more disordered state with freely moving lipid molecules ${ }^{(86,87)}$. Moreover, longer FA chains and a higher content of sphingolipids and sterols in the membrane correlate with an enhanced thickness ${ }^{(88)}$. It has also been observed that asymmetric distribution of glycerophospholipids and sphingolipids between the two leaflets of the neural membrane may lead to dynamic lipid substructures ${ }^{(46)}$. Therefore, the connections between DHA and the membrane physical properties are another important research field deserving further scientific studies.

Future research on the mechanistic aspects connecting DHA and $\mathrm{AD}$ as well as other cognitive ageing disorders should also identify and quantify relevant biomarkers in the plasma and cerebrospinal fluid, bridging the gap between docosanoids, cytokines and neuronal cell changes.

\section{DHA and the cognitive function}

The effects of DHA on cognitive ageing need an understanding of the multiple connections between DHA and the highest degrees of brain activity. Several studies have been conducted 
regarding this subject (Table 3). A deficient level of DHA is related with changes in the operation of cognitive function, namely, in ageing, hyperactivity, $\mathrm{AD}$, schizophrenia and peroxisomal diseases ${ }^{(55)}$. Conversely, higher dietary intake of DHA is linked to better brain health ${ }^{(89)}$. Indeed, DHA is enriched in synaptic membranes, being able to change their fluidity as well as neurotransmitter and receptor densities. These mechanisms whereby DHA affects neural cells have already been described in previous section, but more studies on their details and the way that DHA positively affects cognitive function are warranted. There are several studies of a medical nature pointing to the positive effect of DHA on cognitive function ${ }^{(89)}$, but the full understanding of the underlying biochemistry remains elusive.

Many studies relate to human cognitive function evolution as a result of ageing. For instance, a study on the effects of a $90 \mathrm{~d}$ DHA supplementation $(252 \mathrm{mg} / \mathrm{d})$ on cognitive function in a healthy ageing population did not find any significant impact $^{(90)}$. Besides, it has been argued that there is greater evidence for DHA playing a preventive rather than curative role in dementia ${ }^{(27)}$. This role may be more important in unhealthy populations, for instance, in patients with type 2 diabetes ${ }^{(91)}$. Namely, it is not clear if an adequate brain DHA level can be kept in obesity and insulin-resistant states. Indeed, it is quite possible that the DHA level becomes inadequate, given evidence of greater cognitive decline in individuals with insulin resistance ${ }^{(92)}$. Moreover, it has been reported ${ }^{(93)}$ that reference memory-related learning ability is positively correlated with DHA-derived docosanoids in aged rats. The same study did not find a significant correlation for EPA-derived mediators. Moreover, dietary DHA improves the learning-related spatial memory of DHA-deficient rats ${ }^{(94,95)}$.

There is a lack of robust evidence to evaluate the effect of DHA in diet on the cognitive performance of young healthy adults. Some of the trials that have been done seem to present experimental design shortcomings. For instance, a placebo control is absent ${ }^{(96)}$, sample size is small ${ }^{(97)}$ and duration is too short $^{(98,99)}$. On the other hand, a cross-sectional study on adults aged between 30 and 70 years old showed a positive association between DHA blood levels and scores on cognitive performance tests ${ }^{(11)}$. Against this backdrop, a recent work involving RCT has shown that DHA supplementation has improved both memory and reaction time in healthy young adults $^{(9)}$. It should be remarked that the habitual diet of these young adults (age range 18-45 years) was low in DHA. Moreover, response was modulated by sex - whereas DHA improved episodic memory in women, it improved reaction times of working memory in men ${ }^{(9)}$. Another recent study provided compelling initial evidence that dietary factors affect the connection between physical activity and cognitive performance ${ }^{(100)}$. In particular, high levels of DHA relative to arachidonic acid reduced the negative effects of lower physical activity on performance. The results of these two studies may be related to the fact that DHA accumulates in areas of the brain involved in memory and attention such as the cerebral cortex and hippocampus ${ }^{(101,102)}$. Nevertheless, further observational studies and RCT are warranted in order to achieve a higher degree of certainty and a deeper understanding of the connections.

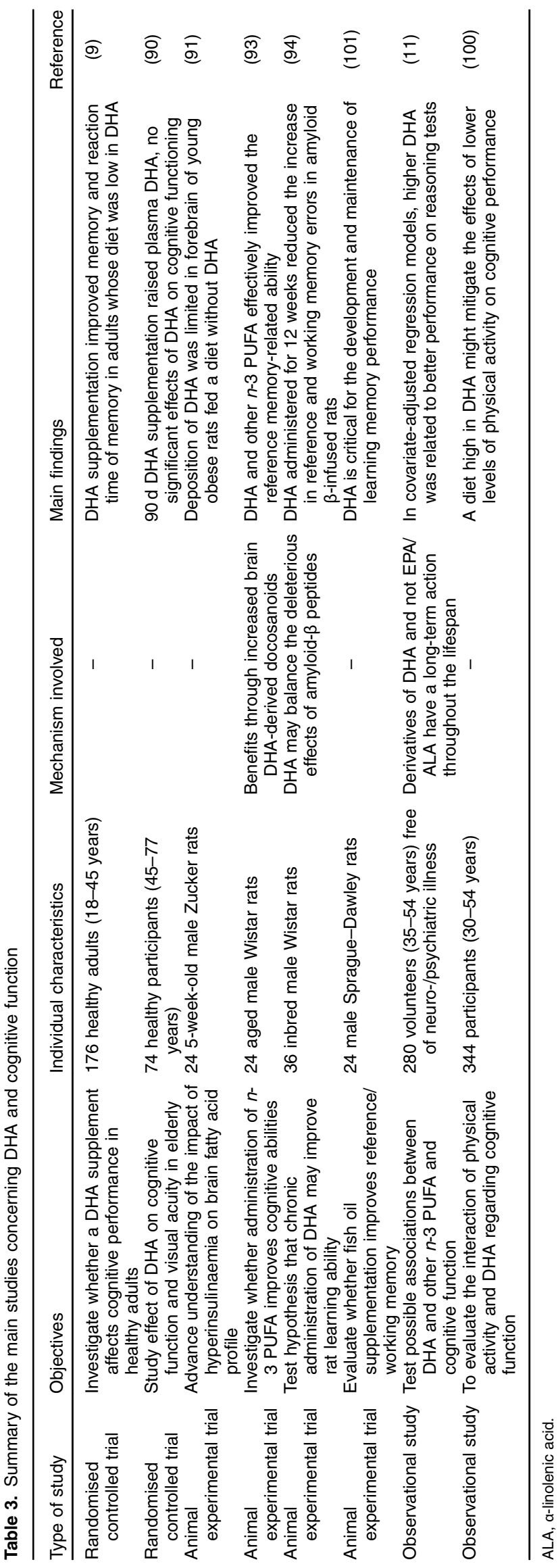




\section{Dietary sources of DHA, bioaccessibility and bioavailability}

The large importance of DHA makes this an essential FA in human nutrition. Diets should be formulated in order to ensure an adequate level of DHA supply. The main source of DHA is seafood, particularly marine fish and shellfish ${ }^{(103)}$. DHA is found in the flesh of both lean and oily fish, with much greater amounts in the latter, and in the liver of some lean fish species, such as cod. There is also fish oil prepared from these raw materials rich in $\mathrm{DHA}^{(76)}$. There are also non-marine sources of DHA. However, DHA contents are only comparable with lean fish in the case of some meat-processing by-products and especially enriched foods. An overview of the DHA content in different sources and their characteristics is presented in Tables 2 and 4 . Since meat, cereals and milk are more important in the Western diet, DHA intake is low ${ }^{(104)}$. Indeed, for a total of approximately $100 \mathrm{mg} \mathrm{DHA} / \mathrm{d}$, fish and seafood products are the largest contributor with $69.9 \mathrm{mg} / \mathrm{d}$, followed by meat products with $19.6 \mathrm{mg} / \mathrm{d}$, and egg products with $5.1 \mathrm{mg} / \mathrm{d}$.

DHA is present primarily as TAG and, to a lesser extent, as NEFA in fish and derived unrefined raw oils ${ }^{(105)}$. In krill oil, a third fraction is found, since a substantial percentage of $n-3$ PUFA (and DHA) is bound in $\mathrm{PL}^{(105)}$. Pharmaceutical-grade, highly concentrated fish oil supplements with DHA bound in ethyl ester, are also available ${ }^{(76)}$.

Oily fish, such as herring, salmon and sardine, are the richest sources of $\mathrm{DHA}^{(106)}$. According to these authors, of thirty-seven commonly consumed types of fish products, DHA is the main $n-3$ PUFA, being on average $65 \%$ of total $n-3$ PUFA $^{(107)}$. It should be remarked that DHA content in fish usually varies with the overall $n-3$ PUFA content. Three main classes of fish products may be differentiated on the basis of DHA content: relatively poor DHA sources (black scabbardfish, catfish, hake, megrim, tilapia); moderately rich DHA sources (halibut, pollock); and very rich DHA sources (herring, mackerel, salmon, sardine), corresponding to the approximate ranges $<300,300-500$, and $>500 \mathrm{mg} / 100 \mathrm{~g}$, respectively ${ }^{(106-111)}$.

For a more detailed presentation of DHA concentrations in different marine sources, Table 2 based on the Portuguese Institute for the Sea and Atmosphere (IPMA) extensive database ${ }^{(111,112)}$ and different papers ${ }^{(113)}$ can be consulted. The six highest DHA contents are found in the European eel, chub mackerel, Atlantic salmon, Atlantic mackerel, gilthead seabream (wild) and sardine, all exceeding $1000 \mathrm{mg} / 100 \mathrm{~g}^{(111,112)}$.

The American Heart Association's recommended daily intake (RDI) is $500 \mathrm{mg} \mathrm{EPA}+$ DHA for individuals without $\mathrm{CHD}^{(114)}$. The European Food Safety Agency has advised $250 \mathrm{mg}$ of $\mathrm{EPA}+\mathrm{DHA}^{(115)}$ and reference values for the EPA + DHA RDI are typically in the $250-500 \mathrm{mg}$ range ${ }^{(116)}$. Specifically for DHA, an RDI of $250 \mathrm{mg}$ has been put forward by ANSES (Agence Nationale de Sécurité Sanitaire de l'Alimentation, de l'Environnement et du Travail) ${ }^{(117)}$. A single weekly meal of $150 \mathrm{~g}$ of chub mackerel, Atlantic salmon or sardine may be more than enough to meet this DHA RDI $(250 \mathrm{mg} / \mathrm{d})$. For seafood moderately rich in DHA, the consumption of two to three weekly meals of $150 \mathrm{~g}$ may also be enough.

The level of DHA in a portion of food that is eaten may be quite different from the bioaccessible level, that is, the DHA concentration that is released from the food matrix into the intestinal lumen after digestion and is available for absorption ${ }^{(118,119)}$. On the other hand, bioavailability is usually defined as the fraction of an oral dose of a substance that reaches the systemic circulation ${ }^{(120)}$. The bioaccessible content is always equal or higher than the bioavailable content ${ }^{(118)}$. Bioaccessibility is usually determined by in vitro simulations of human digestion ${ }^{(118,121)}$. For bioavailability, according to the definition given above, cell lines and transwell assays are used for mimicking the intestinal lining barrier ${ }^{(122)}$ and cell cultures simulating the relevant liver tissues may also be used ${ }^{(123)}$. Bioaccessibility and, as a consequence, bioavailability of DHA may depend on the chemical binding form (DHA bound in ethyl ester, TAG or PL) (Fig. 1), matrix effects (fat and other components content in food), and, in the case of DHA in supplements, galenic form (microencapsulation, emulsification, etc. ${ }^{(105)}$.

\section{DHA biosynthesis routes}

Besides dietary DHA and the bioaccessibility/bioavailability issues, DHA may be biosynthesised in the human body. However, for healthy and non-vegetarian humans, despite the

Table 4. Non-marine DHA dietary sources and their main characteristics, advantages and drawbacks

\begin{tabular}{|c|c|c|c|}
\hline Category & Product & DHA content $(\mathrm{mg} / 100 \mathrm{~g})$ & Product characteristics, advantages and drawbacks \\
\hline \multirow[t]{3}{*}{ Milk* } & Cows' milk, basal diet & $0-10$ & Readily available, but extremely low content \\
\hline & Cows' milk, special diet & $10-30$ & Available, but very low content \\
\hline & Cows' milk, enriched & $30-50$ & Available, but still very low content \\
\hline \multirow[t]{2}{*}{ Eggst } & Chicken eggs, basal diet & $20-40$ & Readily available, but very low content \\
\hline & Chicken eggs, enriched diet & $90-180$ & Available, low content \\
\hline \multirow[t]{6}{*}{ Meatł } & Lamb, muscle & $10-20$ & Readily available, but very low content \\
\hline & Pork, muscle & $10-50$ & Readily available, but very low content \\
\hline & Beef & $10-20$ & Readily available, but very low content \\
\hline & Rabbit, muscle & $10-30$ & Readily available, but very low content \\
\hline & Chicken, basal diet & $10-30$ & Readily available, but very low content \\
\hline & Chicken, linseed diet & $20-50$ & Readily available, but very low content \\
\hline \multirow[t]{2}{*}{ Animal by-products§ } & Pork, subcutaneous fat & $60-320$ & Available, nutritionally unbalanced, low content \\
\hline & Pork, viscera & $10-50$ & Available, but very low content \\
\hline
\end{tabular}

* Values from Fonollá et al. ${ }^{(133)}$ and Klop et al. ${ }^{(134)}$.

$\dagger$ Values from Lemahieu et al. ${ }^{(135)}$.

$\ddagger$ Values from Woods \& Fearon ${ }^{(136)}$ and Zotte \& Szendrö ${ }^{(137)}$

$\S$ Values from Sobol et al. ${ }^{(138)}$. 
availability of the necessary enzymes, there is extremely limited synthesis of DHA in adults ${ }^{(124,125)}$. Unless induced by several years of a vegetarian diet, the human enzymic machinery is very inefficient in converting, for instance, ALA to EPA and DHA. Even with a diet deficient in DHA, the brain cells' ability to synthesise DHA from ALA is very low ${ }^{(126)}$. One study indicates a very low share of plasma ALA, $<0 \cdot 2 \%$, deployed to the synthesis of DHA via $\mathrm{EPA}^{(124)}$. Indeed, it has been claimed an extremely low level of conversion of the precursor ALA to EPA, $<5 \%{ }^{(127)}$, and to DHA, $<0.05 \%^{(128)}$. Several enzymes are required to elongate and desaturate ALA or other shorter and less unsaturated $n$-3 PUFA into DHA. Research has found evidence suggesting that DHA formation may be regulated independently of other FA in the pathway and that DHA binding to PPAR $\alpha$ suppresses transcription of the $\Delta-6$ desaturase gene, thereby down-regulating conversion of ALA to $\mathrm{DHA}^{(129)}$. Indeed, it should be noted that the rate-limiting step in DHA synthesis is precisely the desaturation of ALA by $\Delta-6$ desaturase. An overview of the possible routes for attaining DHA in the human organism, taking into account enzyme action, conversion rates, genetic factors, and dependence on the starting $n$ - 3 PUFA, is presented in Table 5 .

\section{Conclusions}

DHA is mainly found in seafood, being rich sources of DHA such as marine fish and shellfish. Oily fish such as herring, salmon, sardine and tuna provide the highest amount of DHA per meal. DHA intake may be associated with several health endpoints ranging from inflammatory processes, asthma and rheumatoid arthritis to CVD and diabetes mellitus as well as to depression and cancer. Particularly, DHA has an important role in the nervous system, which is highlighted by its prominence in neural tissues. DHA may lead to the formation of docosanoids such as NeuroPs or NPD1. Namely, the action of NPD1 in the central nervous system is influential in different ways. It is known that NPD1 leads to homeostatic signalling in response to cellular and systemic imbalances. Nevertheless, much needs to be known about the mechanisms and roles of NPD1. For instance, NPD1 as a possible modulating agent of transport mediated by ApoE and its effect on $\beta$-APP processing is not fully understood. In spite of this, there seems to be some protection against cognitive decline with ageing and even improved memory and reaction time in healthy young adults. Indeed, for ageing-related MCI, some studies suggest that DHA may improve cognitive abilities. Nonetheless, for healthy subjects or MCI and AD patients, the evidence is still not convincing. In this context, it is worthwhile noting that for ApoE4 allele-negative AD patients, DHA produced a benefit in the cognitive score. Future studies should take the DHA bioavailability issue into account in order to achieve better results. On the other hand, research should try to separate the role of DHA and of EPA through studies using DHA only instead of fish oil rich also in EPA. Moreover, DHA in each main lipid class should be quantified instead of global DHA. Finally, future RCT and observational studies should always take into account the genetic traits of the population, since some effects may only be detected in subgroups with specific alleles.

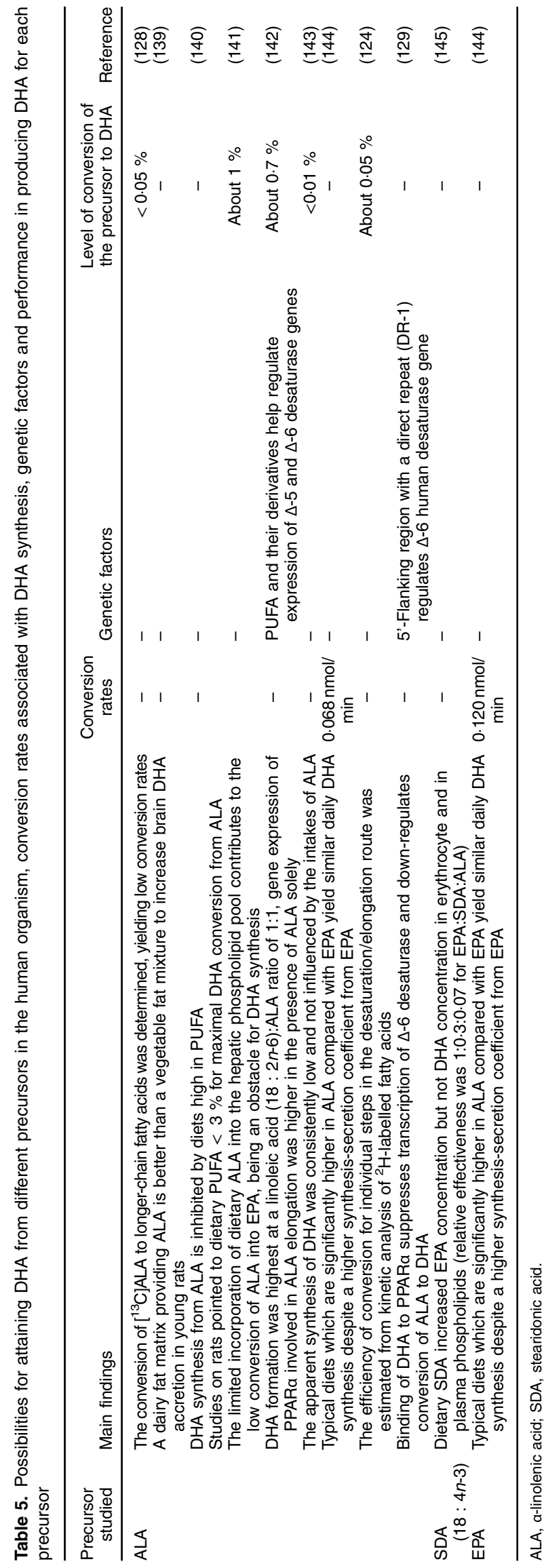




\section{Acknowledgements}

C. A. and C. C. acknowledge the individual Post Doctoral Grant (no. SFRH/BPD/64951/2009 and no. SFRH/BPD/102689/2014, respectively) funded by the 'Fundação para a Ciência e a Tecnologia' (FCT).

The planning as well as the final reading and reviewing of the paper was carried out by all three authors. C. C. wrote three sections, C. A. wrote another three sections, and N. M. B. wrote the last section and coordinated.

There are no conflicts of interest.

\section{References}

1. Freemantle E, Vandal M, Tremblay-Mercier J, et al. (2006) Omega-3 fatty acids, energy substrates, and brain function during aging. Prostaglandins Leukot Essent Fatty Acids $\mathbf{7 5}$, 213-220.

2. Abdin-Sobocki P, Jönsson B, Wittchen HU, et al. (2005) Costs of disorders of the brain in Europe. Eur J Neurol 12, Suppl. 1, 1-27.

3. Hibbeln JR \& Davis JM (2009) Considerations regarding neuropsychiatric nutritional requirements for intakes of omega-3 highly unsaturated fatty acids. Prostaglandins Leukot Essent Fatty Acids 81, 179-186.

4. Milte CM, Parletta N, Buckley JD, et al. (2012) Eicosapentaenoic and docosahexaenoic acids, cognition, and behavior in children with attention-deficit/hyperactivity disorder: a randomized controlled trial. Nutrition 28, 670-677.

5. Ross BM (2009) Omega-3 polyunsaturated fatty acids and anxiety disorders. Prostaglandins Leukot Essent Fatty Acids 81, 309-312.

6. Hellhammer J, Hero T, Franz N, et al. (2012) Omega-3 fatty acids administered in phosphatidylserine improved certain aspects of high chronic stress in men. Nutr Res $\mathbf{3 2}$, 241-250.

7. Stordy BJ (1999) 7-Docosahexaenoic acid: a dietary factor essential for individuals with dyslexia, attention deficit disorder and dyspraxia. In Lipids in Health and Nutrition, pp. 102-114 [JHP Tyman, editor]. Cambridge: Woodhead Publishing Limited.

8. Gow RV \& Hibbeln JR (2014) Omega-3 fatty acid and nutrient deficits in adverse neurodevelopment and childhood behaviors. Child Adolesc Psychiatr Clin N Am 23, 555-590.

9. Stonehouse W, Conlon CA, Podd J, et al. (2013) DHA supplementation improved both memory and reaction time in healthy young adults: a randomized controlled trial. $\mathrm{AmJ}$ Clin Nutr 97, 1134-1143.

10. Mohajeri MH, Troesch B \& Weber P (2015) Inadequate supply of vitamins and DHA in the elderly: implications for brain aging and Alzheimer-type dementia. Nutrition 31, 261-275.

11. Muldoon MF, Ryan CM, Sheu L, et al. (2010) Serum phospholipid docosahexaenonic acid is associated with cognitive functioning during middle adulthood. J Nutr 140, 848-853.

12. Witte AV, Kerti L, Hermannstädter HM, et al. (2014) Long-chain omega-3 fatty acids improve brain function and structure in older adults. Cereb Cortex 24, 3059-3068.

13. Yurko-Mauro K, McCarthy D, Rom D, et al. (2010) Beneficial effects of docosahexaenoic acid on cognition in age related cognitive decline. Alzheimers Dement $\mathbf{6}$, 456-464.
14. Wurtman RJ, Cansev M, Sakamoto T, et al. (2010) Nutritional modifiers of aging brain function: use of uridine and other phosphatide precursors to increase formation of brain synapses. Nutr Rev 68, Suppl. 2, S88-S101.

15. Yurko-Mauro K (2010) Cognitive and cardiovascular benefits of docosahexaenoic acid in aging and cognitive decline. Curr Alzheimer Res 7, 190-196.

16. Gao Q, Niti M, Feng L, et al. (2011) Omega-3 polyunsaturated fatty acid supplements and cognitive decline: Singapore longitudinal aging studies. J Nutr Health Aging 15, 32-35.

17. Velho S, Marques-Vidal P, Baptista F, et al. (2008) Dietary intake adequacy and cognitive function in free-living active elderly: a cross-sectional and short-term prospective study. Clin Nutr 27, 77-86.

18. Chiu CC, Su KP, Cheng TC, et al. (2008) The effects of omega- 3 fatty acids monotherapy in Alzheimer's disease and mild cognitive impairment: a preliminary randomized double-blind placebo controlled study. Prog Neuropsychopharmacol Biol Psychiatry 32, 1538-1544.

19. Kotani S, Sakaguchi E, Warashina S, et al. (2006) Dietary supplementation of arachidonic and docosahexaenoic acids improves cognitive dysfunction. Neurosci Res 56, 159-164.

20. Lee LK, Shahar S, Chin AV, et al. (2013) Docosahexaenoic acid-concentrated fish oil supplementation in subjects with mild cognitive impairment (MCI): a 12-month randomised, double-blind, placebo-controlled trial. Psychopharmacology 225, 605-612.

21. Salem N Jr, Vandal M \& Calon F (2015) The benefit of docosahexaenoic acid for the adult brain in aging and dementia. Prostaglandins Leukot Essent Fatty Acids 92, 15-22.

22. Daiello LA, Gongvatana A, Dunsiger S, et al. (2015) Association of fish oil supplement use with preservation of brain volume and cognitive function. Alzheimers Dement 11, 226-235.

23. Solfrizzi V, Colacicco AM, D'Introno A, et al. (2006) Dietary fatty acids intakes and rate of mild cognitive impairment. The Italian Longitudinal Study on Aging. Exp Gerontol 41, 619-627.

24. Cunnane SC, Chouinard-Watkins R, Castellano CA, et al. (2013) Docosahexaenoic acid homeostasis, brain aging and Alzheimer's disease: can we reconcile the evidence? Prostaglandins Leukot Essent Fatty Acids 88, 61-70.

25. Morris MC, Evans DA, Bienias JL, et al. (2003) Consumption of fish and $n-3$ fatty acids and risk of incident Alzheimer disease. Arch Neurol 60, 940-946.

26. Schaefer EJ, Bongard V, Beiser AS, et al. (2006) Plasma phosphatidylcholine docosahexaenoic acid content and risk of dementia and Alzheimer disease: the Framingham Heart Study. Arch Neurol 63, 1545-1550.

27. Cunnane SC, Plourde M, Pifferi F, et al. (2009) Fish, docosahexaenoic acid and Alzheimer's disease. Prog Lipid Res 48, 239-256.

28. Fotuhi M, Mohassel P \& Yaffe K (2009) Fish consumption, long-chain omega- 3 fatty acids and risk of cognitive decline or Alzheimer disease: a complex association. Nat Clin Pract Neurol 5, 140-152.

29. Devore EE, Grodstein F, van Rooij FJ, et al. (2009) Dietary intake of fish and omega-3 fatty acids in relation to long-term dementia risk. Am J Clin Nutr 90, 170-176.

30. Wu S, Ding Y, Wu F, et al. (2015) Omega-3 fatty acids intake and risks of dementia and Alzheimer's disease: a meta-analysis. Neurosci Biobehav Rev 48, 1-9. 
31. Cardoso C, Bandarra N, Lourenço H, et al. (2010) Methylmercury risks and EPA+DHA benefits associated with seafood consumption in Europe. Risk Anal 30, 827-840

32. Quinn JF, Raman R, Thomas RG, et al. (2010) Docosahexaenoic acid supplementation and cognitive decline in Alzheimer disease: a randomized trial. J Am Med Assoc 304, 1903-1911.

33. Corrigan FM, Van Rhijn AG, Ijomah G, et al. (1991) Tin and fatty acids in dementia. Prostaglandins Leukot Essent Fatty Acids 43, 229-238.

34. Cunnane SC, Schneider JA, Tangney C, et al. (2012) Plasma and brain fatty acid profiles in mild cognitive impairment and Alzheimer's disease. J Alzheimers Dis 29, 691-697.

35. Igarashi M, Ma K, Gao F, et al. (2011) Disturbed choline plasmalogen and phospholipid fatty acid concentrations in Alzheimer disease prefrontal cortex. J Alzheimer Dis 24, 507-517.

36. Whelan J (2008) (n-6) and (n-3) Polyunsaturated fatty acids and the aging brain: food for thought. $J$ Nutr $\mathbf{1 3 8}$, 2521-2522.

37. Hanhoff T, Lücke C \& Spener F (2002) Insights into binding of fatty acids by fatty acid binding proteins. Mol Cell Biochem 239, 45-54.

38. Storch J \& Thumser AE (2010) Tissue-specific functions in the fatty acid-binding protein family. $J$ Biol Chem 285 , 32679-32683.

39. Scott BL \& Bazan NG (1989) Membrane docosahexaenoate is supplied to the developing brain and retina by the liver. Proc Nat Acad Sci U S A 86, 2903-2907.

40. Mitchell RW \& Hatch GM (2011) Fatty acid transport into the brain: of fatty acid fables and lipid tails. Prostaglandins Leukotrienes Essent Fatty Acids 85, 293-302.

41. Hamilton JA \& Brunaldi K (2007) A model for fatty acid transport into the brain. J Mol Neurosci 33, 12-17.

42. Ratnayake WMN \& Hollywood R (1997) Influence of diet on human milk fatty acid composition. Abstracts, 88th AOCS Annual Meeting and Expo: 96. Seattle: AOCS Press.

43. Beydoun MA, Kaufman JS, Satia JA, et al. (2007) Plasma n-3 fatty acids and the risk of cognitive decline in older adults: the atherosclerosis risk in communities study. Am J Clin Nutr 85, 1103-1111.

44. Laurin D, Verreault R, Lindsay J, et al. (2003) Omega-3 fatty acids and risk of cognitive impairment and dementia. J Alzheimers Dis 5, 315-322.

45. Manzato E, Roselli della Rovere G, Zambon S, et al. (2003) Cognitive functions are not affected by dietary fatty acids in elderly subjects in the ProVA study population. Aging Clin Exp Res 15, 83-86.

46. Glomset JA (2006) Role of docosahexaenoic acid in neuronal plasma membranes. Sci STKE 321, pe6.

47. Kennedy EM \& Weiss SB (1956) The function of cytidine coenzymes in the biosynthesis of phospholipids. $J$ Biol Chem 222, 193-214.

48. Wurtman RJ, Ulus IH, Cansev M, et al. (2006) Synaptic proteins and phospholipids are increased in gerbil brain by administering uridine plus docosahexaenoic acid orally. Brain Res 1088, 83-92.

49. Cansev M \& Wurtman RJ (2007) Chronic administration of docosahexaenoic acid or eicosapentaenoic acid, but not arachidonic acid, alone or in combination with uridine, increases brain phosphatide and synaptic protein levels in gerbils. Neuroscience 148, 421-431.

50. Svennerholm L (1968) Distribution and fatty acid composition of phosphoglycerides in normal human brain. J Lipid Res 9, 570-579.
51. Martínez M \& Mougan I (1998) Fatty acid composition of human brain phospholipids during normal development. J Neurochem 71, 2528-2533.

52. Conquer JA \& Holub BJ (1997) Dietary docosahexaenoic acid as a source of eicosapentaenoic acid in vegetarians and omnivores. Lipids 32, 341-345.

53. Sawazaki S, Salem NJ Jr \& Kim HY (1994) Lipoxygenation of docosahexaenoic acid by the rat pineal body. J Neurochem 62, 2437-2447.

54. Long EK, Murphy TC, Leiphon LJ, et al. (2008) Trans-4-hydroxy-2-hexenal is a neurotoxic product of docosahexaenoic $(22: 6 ; n-3)$ acid oxidation. J Neurochem 105, 714-724.

55. Bazan NG, Molina MF \& Gordon WC (2011) Docosahexaenoic acid signalolipidomics in nutrition: significance in aging, neuroinflammation, macular degeneration, Alzheimer's, and other neurodegenerative diseases. Ann Rev Nutr 31, 321-351.

56. Porta A, Pasi M, Brunoldi E, et al. (2013) Biology and chemistry of neuroprostanes. First total synthesis of $17-\mathrm{A}_{4}{ }^{-}$ NeuroP: validation of a convergent strategy to a number of cyclopentenone neuroprostanes. Chem Phys Lipids 174, 64-74.

57. Bazan NG, Birkle DL \& Reddy TS (1984) Docosahexaenoic acid $(22: 6, n-3)$ is metabolized to lipoxygenase reaction products in the retina. Biochem Biophys Res Commun 125 , 741-747.

58. Bazan NG (2007) Homeostatic regulation of photoreceptor cell integrity: significance of the potent mediator neuroprotectin D1 biosynthesized from docosahexaenoic acid: the Proctor Lecture. Invest Ophthalmol Visual Sci 48, 4866-4881.

59. Bazan NG (2009) Neuroprotectin D1-mediated antiinflammatory and survival signaling in stroke, retinal degenerations, and Alzheimer's disease. J Lipid Res 50, S400-S405.

60. Calandria JM, Marcheselli VL, Mukherjee PK, et al. (2009) Selective survival rescue in 15-lipoxygenase-1-deficient retinal pigment epithelial cells by the novel docosahexaenoic acid-derived mediator, neuroprotectin D1. J Biol Chem 284, 17877-17882.

61. Lukiw WJ, Cui J, Marcheselli VL, et al. (2005) A role for docosahexaenoic acid-derived neuroprotectin D1 in neural cell survival and Alzheimer disease. J Clin Invest 115, 2774-2783.

62. Brand A, Schonfeld E, Isharel I, et al. (2008) Docosahexaenoic acid-dependent iron accumulation in oligodendroglia cells protects from hydrogen peroxide-induced damage. J Neurochem 105, 1325-1335.

63. Lukiw WJ \& Bazan NG (2008) Docosahexaenoic acid and the aging brain. J Nutr 138, 2510-2514.

64. Mukherjee PK, Chawla A, Loayza MS, et al. (2007) Docosanoids are multifunctional regulators of neural cell integrity and fate: significance in aging and disease. Prostaglandins Leukot Essent Fatty Acids 77, 233-238.

65. Rapoport SI, Rao JS \& Igarashi M (2007) Brain metabolism of nutritionally essential polyunsaturated fatty acids depends on both the diet and the liver. Prostaglandins Leukot Essent Fatty Acids 77, 251-261.

66. Cole GM \& Frautschy SA (2006) Docosahexaenoic acid protects from amyloid and dendritic pathology in an Alzheimer's disease mouse model. Nutr Health 18, 249-259.

67. Kim HY, Akbar M, Lau A, et al. (2000) Inhibition of neuronal apoptosis by docosahexaenoic acid (22:6 n-3). J Biol Chem 275, 35215-35223.

68. Lukiw WJ (2008) Emerging amyloid $\beta$ (A $\beta$ ) peptide modulators for the treatment of Alzheimer's disease (AD). Expert Opin Emerg Drugs 13, 255-271. 
69. Lukiw WJ (2006) Cholesterol and 24S-hydroxycholesterol trafficking in Alzheimer's disease. Expert Rev Neurother $\mathbf{6}$, 683-693.

70. Bu G (2009) Apolipoprotein $\mathrm{E}$ and its receptors in Alzheimer's disease: pathways, pathogenesis and therapy. Nat Rev Neurosci 10, 333-344.

71. Hauser PS, Narayanaswami V \& Ryan RO (2011) Apolipoprotein E: from lipid transport to neurobiology. Prog Lipid Res 50, 62-74.

72. Chouinard-Watkins R, Rioux-Perreault C, Fortier M, et al. (2013) Disturbance in uniformly ${ }^{13}$ C-labelled DHA metabolism in elderly human subjects carrying the apoE $\varepsilon 4$ allele. Br J Nutr 110, 1751-1759.

73. Vandal M, Alata W, Tremblay C, et al. (2014) Reduction in DHA transport to the brain of mice expressing human APOE4 compared to APOE2. J Neurochem 129, 516-526.

74. Plourde M, Vohl MC, Vandal M, et al. (2009) Plasma $n-3$ fatty acid response to an $n-3$ fatty acid supplement is modulated by apoE $\varepsilon 4$ but not by the common PPAR- $\alpha$ L162V polymorphism in men. Br J Nutr 102, 1121-1124.

75. Bradbury J (2011) Docosahexaenoic acid (DHA): an ancient nutrient for the modern human brain. Nutrients $\mathbf{3}$, 529-554.

76. Calder PC (2015) Marine omega-3 fatty acids and inflammatory processes: effects, mechanisms and clinical relevance. Biochim Biophys Acta 1851, 469-484.

77. Serhan CN (2005) Mediator lipidomics. Prostaglandins Other Lipid Mediat 77, 4-14.

78. Freund-Levi Y, Hjorth E, Lindberg C, et al. (2009) Effects of omega- 3 fatty acids on inflammatory markers in cerebrospinal fluid and plasma in Alzheimer's disease: The OmegAD study. Dement Geriatr Cogn Disord 27, 481-490.

79. Meinert CL \& Breitner JC (2008) Chronic disease long-term drug prevention trials: lessons from the Alzheimer's Disease Anti-inflammatory Prevention Trial (ADAPT). Alzheimers Dement 4, S7-S14.

80. Patel NS, Paris D, Mathura V, et al. (2005) Inflammatory cytokine levels correlate with amyloid load in transgenic mouse models of Alzheimer's disease. J Neuroinflammation 2, 9.

81. Schultzberg M, Lindberg C, Forslin ÅA, et al. (2007) Inflammation in the nervous system - physiological and pathophysiological aspects. Physiol Behav 92, 121-128.

82. Srinivasarao P, Narayanareddy K, Vajreswari A, et al. (1997) Influence of dietary fat on the activities of subcellular membrane-bound enzymes from different regions of the brain. Neurochem Int 31, 789-794.

83. Klose C, Surma MA \& Simons K (2013) Organellar lipidomics - background and perspectives. Cur Opin Cell Biol 25, 406-413.

84. Lee AG (2011) Biological membranes: the importance of molecular detail. Trends Biochem Sci 36, 493-500.

85. Shevchenko A \& Simons K (2010) Lipidomics: coming to grips with lipid diversity. Nat Rev Mol Cell Biol 11, 593-598.

86. Kahya N, Scherfeld D, Bacia K, et al. (2003) Probing lipid mobility of raft-exhibiting model membranes by fluorescence correlation spectroscopy. J Biol Chem 278, 28109-28115.

87. Silvius JR (1982) Thermotropic phase transitions of pure lipids in model membranes and their modification by membrane proteins. In Lipid-Protein Interactions vol. 2, pp. 239-281 [PC Jost and OH Griffith, editors]. New York: John Wiley \& Sons.

88. Surma MA, Klose C, Klemm RW, et al. (2011) Generic sorting of raft lipids into secretory vesicles in yeast. Traffic 12, 1139-1147.
89. Burri L (2015) Krill oil supplementation and cognitive function. In Diet and Nutrition in Dementia and Cognitive Decline, chapter 96 pp. 1031-1038 [CR Martin and V Preedy, editors]. Oxford: Academic Press.

90. Stough C, Downey L, Silber B, et al. (2012) The effects of 90-day supplementation with the omega-3 essential fatty acid docosahexaenoic acid (DHA) on cognitive function and visual acuity in a healthy aging population. Neurobiol Aging 33, 824e1-824e3.

91. Zhao J, Gillam ME, Taylor CG, et al. (2011) Deposition of docosahexaenoic acid (DHA) is limited in forebrain of young obese $\mathrm{fa} / \mathrm{fa}$ Zucker rats fed a diet high in $\alpha$-linolenic acid but devoid of DHA. J Nutr Biochem 22, 835-842.

92. Young SE, Mainous AG III \& Carnemolla M (2006) Hyperinsulinemia and cognitive decline in a middleaged cohort. Diabetes Care 29, 2688-2693.

93. Hashimoto M, Katakura M, Tanabe Y, et al. (2015) n-3 Fatty acids effectively improve the reference memory-related learning ability associated with increased brain docosahexaenoic acid-derived docosanoids in aged rats. Biochim Biophys Acta 1851, 203-209.

94. Hashimoto M, Tanabe Y, Fujii Y, et al. (2005) Chronic administration of docosahexaenoic acid ameliorates the impairment of spatial cognition learning ability in amyloid $\beta$-infused rats. J Nutr 135, 549-555.

95. Mills JD, Hadley K \& Bailes JE (2011) Dietary supplementation with the omega-3 fatty acid docosahexaenoic acid in traumatic brain injury. Neurosurgery 68, 474-481.

96. Fontani G, Corradeschi F, Felici A, et al. (2005) Cognitive and physiological effects of omega-3 polyunsaturated fatty acid supplementation in healthy subjects. Eur J Clin Invest 35, 691-699.

97. Antypa N, Van der Does AJW, Smelt AHM, et al. (2009) Omega-3 fatty acids (fish-oil) and depression-related cognition in healthy volunteers. J Psychopharmacol 23, 831-840.

98. Jackson PA, Deary ME, Reay JL, et al. (2012) No effect of 12 weeks' supplementation with $1 \mathrm{~g}$ DHA-rich or EPA-rich fish oil on cognitive function or mood in healthy young adults aged 18-35 years. Br J Nutr 107, 1232-1243.

99. Rogers PJ, Appleton KM, Kessler D, et al. (2008) No effect of $n-3$ long-chain polyunsaturated fatty acid (EPA and DHA) supplementation on depressed mood and cognitive function: a randomized controlled trial. Br J Nutr 99, 421-431.

100. Leckie RL, Manuck SB, Bhattacharjee N, et al. (2014) Omega-3 fatty acids moderate effects of physical activity on cognitive function. Neuropsychologia 59, 103-111.

101. Chung WL, Chen JJ \& Su HM (2008) Fish oil supplementation of control and (n-3) fatty acid-deficient male rats enhances reference and working memory performance and increases brain regional docosahexaenoic acid levels. J Nutr 138, 1165-1171.

102. Gamoh S, Hashimoto M, Sugioka K, et al. (1999) Chronic administration of docosahexaenoic acid improves reference memory-related learning ability in young rats. Neuroscience 93, 237-241.

103. Ackman RG, Ratnayake WMN \& Olsson B (1988) The "basic" fatty acid composition of Atlantic fish oils: potential similarities useful for enrichment of polyunsaturated fatty acids by urea complexation. JAOCS 65, 136-138.

104. Howe P, Meyer B, Record S, et al. (2006) Dietary intake of long-chain omega-3 polyunsaturated fatty acids: contribution of meat sources. Nutrition 22, 47-53.

105. Schuchardt JP \& Hahn A (2013) Bioavailability of longchain omega-3 fatty acids. Prostaglandins Leukot Essent Fatty Acids 89, 1-8. 
106. Harris WS, Kris-Etherton PM \& Harris KA (2008) Intakes of long chain omega-3 fatty acid associated with reduced risk for death from coronary heart disease in healthy adults. Curr Atheroscler Rep 10, 503-509.

107. Afonso C, Lourenço HM, Cardoso C, et al. (2013) From fish chemical characterisation to the benefit-risk assessment - Part A. Food Chem 137, 99-107.

108. Afonso C, Cardoso C, Lourenço HM, et al. (2013) Evaluation of hazards and benefits associated with the consumption of six fish species from the Portuguese coast. J Food Comp Anal 32, 59-67.

109. Bandarra NM, Batista I, Nunes ML, et al. (1997) Seasonal changes in lipid composition of sardine (Sardina pilchardus). J Food Sci 62, 40-42.

110. Costa S, Afonso C, Cardoso C, et al. (2015) Fatty acids, mercury, and methylmercury bioaccessibility in salmon (Salmo salar) using an in vitro model: effect of culinary treatment. Food Chem 185, 268-276.

111. Nunes ML, Bandarra N, Oliveira L, et al. (2006) Composition and nutritional value of fishery products consumed in Portugal. In Seafood Research from Fish to Dish Quality, Safety and Processing of Wild and Farmed Fish, pp. 477-487 [JB Luten, C Jacobsen, K Bekaert, A Saebø and J Oehlenschläger, editors]. Wageningen: Wageningen Academic Publishers.

112. Bandarra NM, Calhau MA, Oliveira L, et al. (2004) Composição e valor nutricional dos produtos da pesca mais consumidos em Portugal (Composition and Nutritional Value of Most Consumed Seafood Products in Portugal) vol. 11, pp. 1-103. Lisbon: Publicações Avulsas do IPIMAR/INIAP. https://www.ipma.pt/resources.www/ docs/publicacoes.site/pescado/inicio.htm

113. Peinado I, Girón J, Koutsidis G, et al. (2014) Chemical composition, antioxidant activity and sensory evaluation of five different species of brown edible seaweeds. Food Res Int 66, 36-44.

114. Kris-Etherton P, Harris W, Appel L, et al. (2002) Fish consumption, fish oil, omega-3 fatty acids, and cardiovascular disease. Circulation 106, 2747-2757.

115. EFSA Panel on Dietetic Products, Nutrition and Allergies (NDA) (2010) Scientific Opinion on Dietary Reference Values for fats, including saturated fatty acids, polyunsaturated fatty acids, monounsaturated fatty acids, trans fatty acids, and cholesterol. EFSA J 8, 1461.

116. EFSA Panel on Dietetic Products, Nutrition and Allergies (NDA) (2012) Scientific Opinion on the Tolerable Upper Intake Level of eicosapentaenoic acid (EPA), docosahexaenoic acid (DHA) and docosapentaenoic acid (DPA). EFSA J 10, 2815.

117. ANSES (Agence nationale de sécurité sanitaire de l'alimentation, de l'environnement et du travail) (2010) Opinion of the French Food Safety Agency on the update of French population reference intakes (ANCs) for fatty acids. https:// www.anses.fr/en/system/files/NUT2006sa0359EN.pdf

118. Cardoso C, Afonso C, Lourenço H, et al. (2015) Bioaccessibility assessment methodologies and their consequences for the risk-benefit evaluation of food. Trends Food Sci Technol 41, 5-23.

119. Paustenbach DJ (2000) The practice of exposure assessment: a state-of-the-art. J Toxicol Environ Health B Crit Rev 3, 179-291.

120. Schumann K, Classen HG, Hages M, et al. (1997) Bioavailability of oral vitamins, minerals and trace elements in perspective. Drug Res 47, 369-380.

121. Versantvoort CHM, Oomen AG, Van de Kamp E, et al. (2005) Applicability of an in vitro digestion model in assessing the bioaccessibility of mycotoxins from food. Food Chem Toxicol 43, 31-40.

122. Minoo P, Moyer MP \& Jass JR (2007) Role of BRAF-V600E in the serrated pathway of colorectal tumourigenesis. J Pathol 212, 124-133.

123. LeCluyse EL, Witek RP, Andersen ME, et al. (2012) Organotypic liver culture models: meeting current challenges in toxicity testing. Crit Rev Toxicol 42, 501-548.

124. Pawlosky RJ, Hibbeln JR, Novotny JA, et al. (2001) Physiological compartmental analysis of $\alpha$-linolenic acid metabolism in adult humans. J Lipid Res 42, 1257-1265.

125. Plourde M \& Cunnane SC (2007) Extremely limited synthesis of long chain polyunsaturates in adults: implications for their dietary essentiality and use as supplements. Appl Physiol Nutr Metab 32, 619-634.

126. Igarashi M, DeMar JJC, Ma K, et al. (2007) Docosahexaenoic acid synthesis from $\alpha$-linolenic acid by rat brain is unaffected by dietary $n-3$ PUFA deprivation. J Lipid Res 48, 1150-1158.

127. Brenna JT (2002) Efficiency of conversion of $\alpha$-linolenic acid to long chain $n$-3 fatty acids in man. Cur Opin Clin Nutr Metab Care 5, 127-132.

128. Burdge GC, Finnegan YE, Minihane AM, et al. (2003) Effect of altered dietary $n-3$ fatty aid intake upon plasma lipid fatty acid composition, conversion of $\left[{ }^{13} \mathrm{C}\right] \alpha$-linolenic acid to longer-chain fatty acids and partitioning towards $\beta$-oxidation in older men. Br J Nutr 90, 311-321.

129. Tang C, Cho HP, Nakamura MT, et al. (2003) Regulation of human $\Delta-6$ desaturase gene transcription: identification of a functional direct repeat-1 element. J Lipid Res 44, 686-695.

130. Makri A, Bellou S, Birkou M, et al. (2011) Lipid synthesized by micro-algae grown in laboratory- and industrial-scale bioreactors. Eng Life Sci 11, 52-58.

131. Patil V, Källqvist T, Olsen E, et al. (2007) Fatty acid composition of 12 microalgae for possible use in aquaculture feed. Aquat Int 15, 1-9.

132. Taoka Y, Nagano N, Okita Y, et al. (2011) Effect of Tween 80 on the growth, lipid accumulation and fatty acid composition of Thraustochytrium aureum ATCC 34304. J Biosci Bioeng 111, 420-424.

133. Fonollá J, López-Huertas E, Machado FJ, et al. (2009) Milk enriched with "healthy fatty acids" improves cardiovascular risk markers and nutritional status in human volunteers. Nutrition 25, 408-414.

134. Klop G, Hatew B, Bannink A, et al. (2016) Feeding nitrate and docosahexaenoic acid affects enteric methane production and milk fatty acid composition in lactating dairy cows. J Dairy Sci 99, 1161-1172.

135. Lemahieu C, Bruneel C, Ryckebosch E, et al. (2015) Impact of different omega-3 polyunsaturated fatty acid (n-3 PUFA) sources (flaxseed, Isochrysis galbana, fish oil and DHA gold) on $n$-3 LC-PUFA enrichment (efficiency) in the egg yolk. J Funct Foods 19, 821-827.

136. Woods VB \& Fearon AM (2009) Dietary sources of unsaturated fatty acids for animals and their transfer into meat, milk, and eggs: a review. Livest Sci 126, 1-20.

137. Zotte A \& Szendrö Z (2011) The role of rabbit meat as functional food. Meat Sci 88, 319-331.

138. Sobol M, Skiba G \& Raj S (2015) Effect of n-3 polyunsaturated fatty acid intake on its deposition in the body of growing-finishing pigs. Anim Feed Sci Technol 208, 107-118.

139. Delplanque B, Du Q, Agnani G, et al. (2013) A dairy fat matrix providing $\alpha$-linolenic acid (ALA) is better than a vegetable fat mixture to increase brain DHA accretion in young rats. Prostaglandins Leukot Essent Fatty Acids 88, 115-120. 
140. Gibson RA, Neumann MA, Lien EL, et al. (2013) Docosahexaenoic acid synthesis from $\alpha$-linolenic acid is inhibited by diets high in polyunsaturated fatty acids. Prostaglandins Leukot Essent Fatty Acids 88, 139-146.

141. Goyens PL, Spilker ME, Zock PL, et al. (2005) Compartmental modeling to quantify $\alpha$-linolenic acid conversion after longer term intake of multiple tracer boluses. J Lipid Res $\mathbf{4 6}$, 1474-1483.

142. Harnack K, Anderson G \& Somoza V (2009) Quantitation of $\alpha$-linolenic acid elongation to eicosapentaenoic and docosahexaenoic acid as affected by the ratio of $n 6 / n 3$ fatty acids. Nutr Metab 6, 8 .
143. Hussein N, Ah-Sing E, Wilkinson P, et al. (2005) Relative rates of long chain conversion of $\left[{ }^{13} \mathrm{C}\right]$ linoleic and $\alpha$-linolenic acid in response to marked changes in their dietary intake in male adults. J Lipid Res 46, 269-280.

144. Metherel AH, Domenichiello AF, Kitson AP, et al. (2016) Whole-body DHA synthesis-secretion kinetics from plasma eicosapentaenoic acid and $\alpha$-linolenic acid in the free-living rat. Biochim Biophys Acta 1867, 997-1004.

145. James MJ, Ursin MV \& Cleland LG (2003) Metabolism of stearidonic acid in human subjects: comparison with the metabolism of other $n-3$ fatty acids. Am J Clin Nutr 77, $1140-1145$. 